\title{
Seletividade de Herbicidas Aplicados em Pós-Emergência para a Cultura da Mandioquinha-Salsa ${ }^{1}$
}

\author{
Peruvian Carrot Tolerance to Post-Emergence Herbicides
}

\begin{abstract}
FREITAS, R.S. ${ }^{2}$, PEREIRA, P.C. ${ }^{3}$, SEDIYAMA, M.A.N. ${ }^{4}$, FERREIRA, F.A. ${ }^{5}$ e SEDIYAMA, T. ${ }^{5}$
RESUMO - A suscetibilidade da cultura de mandioquinha-salsa a herbicidas aplicados em pós-emergência foi avaliada, cultivando-se três mudas pré-enraizadas e uniformes por vaso de cinco litros de capacidade, preenchidos com solo Podzólico Vermelho-Amarelo Câmbico, fase terraço, coletado na camada de $0-20 \mathrm{~cm}$. Utilizou-se o delineamento de blocos ao acaso, com três repetições e 39 tratamentos obtidos do arranjo fatorial (13 x 3), sendo 12 herbicidas e uma testemunha sem herbicida e três doses (uma dose baixa, uma média e uma alta). As doses dos herbicidas (em g ha ${ }^{-1}$ ) foram: bentazon (600, 720 e 960), clethodim (84, 96 e 108), fenoxaprop-p-ethyl $(68,90$ e 110), flazasulfuron $(50,75,100)$, fluazifop-p-butil $(94,187$ e 250), halosulfuron $(75,112$ e 150), imazamox (28, 35 e 42), linuron (900, 1.350 e 1.800), oxadiazon (500, 750 e 1.000), propaquizafop $(100,125$ e 150), sethoxydim $(184,230$ e 276$)$ e amônio-glufosinato $(200,300$ e 400). A colheita das plantas foi realizada aos 49 dias após a aplicação dos tratamentos (DAA). Os herbicidas halosulfuron, flazasulfuron, imazamox e bentazon causaram alta toxicidade e prejuízos para as características avaliadas, sendo considerados não-seletivos para a cultura. O linuron e oxadiazon, nas doses baixa e média, e o amônio-glufosinato, na dose baixa, proporcionaram toxicidade às plantas de mandioquinha-salsa no início das avaliações, porém observou-se boa recuperação a partir de 28 DAA. O fluazifop-p-butil foi seletivo nas menores doses utilizadas. Os herbicidas clethodim, fenoxaprop-p-ethyl, propaquizafop e sethoxydim foram os mais seletivos.
\end{abstract}

Palavras-chave: Arracacia xanthorrhiza, mandioquinha-salsa, seletividade.

ABSTRACT - The tolerance of peruvian carrot to post-emergence herbicides was evaluated. Three pre-rooted uniform seedlings were grown in 5-liter pots with Red Yellow Podzolic Cambic soil, terrace phase, collected from a $0-20 \mathrm{~cm}$ depth layer The experimental design was a $13 \times 3$ factorial arrangement [twelve herbicides, a control without herbicide, and three herbicide doses (low, medium and high)] with 39 treatments distributed in randomized blocks, with three

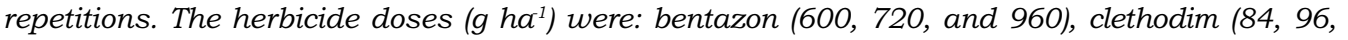
and 108), fenoxaprop-p-ethyl (68, 90, and 110), flazasulfuron (50, 75, and 100), fluazifop-pbutyl (94, 187, and 250), halosulfuron (75, 112, and 150), imazamox (28, 35, and 42), linuron (900, 1,350, and 1,800), oxadiazon (500, 750, and 1,000), propaquizafop (100, 125, and 150), sethoxydin (184, 230, and 276), and ammonium-glufosinate (200, 300, and 400). The plants were harvested at 49 days after treatment application (DAA). The herbicides halosulfuron, flazasulfuron, imazamox and bentazon caused high toxicity and damage to the crop, being non-selective for Peruvian carrot. Low and medium doses of linuron and oxadiazon, and low dose of ammonium-glufosinate caused toxicity just after spraying, but the crop showed good recovery from 28 DAA. Fluazifop-p-butyl was selective in low doses. Clethodim, fenoxaprop-pethyl, propaquizafop, and sethoxydin were the most selective to Peruvian carrot.

Key words: Arracacia xanthorrhiza, peruvian carrot, selectivity.

Recebido para publicação em 12.8.2003 e na forma revisada em 5.3.2004.

Trabalho financiado pela FAPEMIG.

2 Doutorando em Fitotecnia, Universidade Federal de Viçosa - UFV, 36570-000 Viçosa-MG, $<$ freitasrs@hotmail.com $>$. ${ }^{3}$ Bolsista FAPEMIG - EPAMIG, Vila Giannetti, 46, Campus da UFV, 36570-000 Viçosa-MG. ${ }^{4}$ EPAMIG, Vila Gianetti, 46, Campus da UFV. ${ }^{5}$ Prof. do Dep. de Fitotecnia da UFV. 


\section{INTRODUÇÃO}

A mandioquinha-salsa (Arracacia xanthorrhiza Bancroft) é uma hortaliça dicotiledônea, pertencente à família Apiaceae (Umbeliferae). É originária da região andina da América do Sul e foi introduzida no Brasil, provavelmente, a partir de 1900 (Casali \& Sediyama, 1997). Em clima tropical e subtropical de altitude, normalmente superior a $800 \mathrm{~m}$, a cultura da mandioquinha-salsa tem melhor desenvolvimento, sendo a temperatura o fator principal. Altas temperaturas prejudicam o seu desenvolvimento em todas as fases do ciclo, enquanto os efeitos do fotoperíodo e da luminosidade são pouco conhecidos (Zanin \& Casali, 1984).

As mudas são plantadas no espaçamento de $1,0 \times 0,4 \mathrm{~m}$ a 0,7 $\times 0,3 \mathrm{~m}$ e apresentam emergência e crescimento inicial lentos e longo ciclo vegetativo; com isso, o manejo cultural é um processo caro, principalmente porque as plantas daninhas são controladas utilizando capina manual com enxada, que pode ainda danificar o sistema radicular da cultura. A cultura emprega intensa mão-de-obra (100 homens $\mathrm{dia}^{-1} \mathrm{ha}^{-1}$ ), principalmente nas fases de plantio, controle de plantas daninhas e colheita (Madeira et al., 2002).

O uso de herbicida aumenta a eficácia do programa de manejo de plantas daninhas, tornando-o mais rápido e econômico, permitindo que o produtor empregue a mão-de-obra disponível na propriedade em outras atividades. Devido à falta de informação sobre herbicidas seletivos para a cultura da mandioquinhasalsa, muitos agricultores já vêm utilizando indevidamente alguns produtos sem amparo da pesquisa e burlando a lei que regulamenta o seu uso.

Segundo Harrinson \& Dukes (1996) e Grey et al. (2000), uma das limitações ao controle químico das plantas daninhas, em muitas hortaliças, é a pouca opção de herbicidas seletivos registrados; para a cultura da mandioquinha-salsa, essas informações são inexistentes.

Os herbicidas propaquizafop, clethodim, sethoxydim e fenoxaprop-p-ethyl, assim como o fluazifop-p-butil, são usados no controle de apenas espécies gramíneas (Weller, 2000). Trabalhos realizados com cenoura e cebola comprovam a seletividade e a eficiência destes produtos como graminicidas (Zagonel et al., 1999, 2000). No entanto, Vidal et al. (2000) observaram que o fluazifop-p-butil causou toxicidade em cucurbitáceas nas doses de 376 e $752 \mathrm{~g} \mathrm{ha}^{-1}$. Esses resultados sugerem a necessidade de pesquisa com herbicidas desse grupo e doses, inclusive para outras espécies dicotiledôneas.

O objetivo deste trabalho foi avaliar a tolerância da mandioquinha-salsa a herbicidas aplicados em pós-emergência da cultura.

\section{MATERIAL E MÉTODOS}

O experimento foi realizado na Empresa de Pesquisa Agropecuária de Minas Gerais (EPAMIG), em Viçosa, no período de julho a setembro de 2001, utilizando delineamento de blocos ao acaso com três repetições. Os tratamentos foram dispostos em arranjo fatorial 13 x 3: uma testemunha sem herbicida e 12 herbicidas em três doses (baixa, média e alta), apresentadas na Tabela 1. Cada unidade experimental foi constituída por um vaso, com três mudas uniformes.

As mudas do clone "Amarelo de Carandaî", provenientes do município de Simonésia-MG, foram destacadas das touceiras e preparadas para o plantio, com cortes transversais no ápice e na base, deixando os rebentos com, aproximadamente, quatro centímetros de comprimento (Casali \& Sediyama, 1997). Posteriormente, as mudas foram imersas, por cinco minutos, em solução de hipoclorito de sódio a $10 \%$ e pH 7,0 ; após a secagem à sombra, elas foram plantadas em canteiro de enraizamento, preparado com mistura de terriço, esterco e areia (2:1:1 - v:v:v), no espaçamento de $10 \times 10 \mathrm{~cm}$, seguindo a metodologia proposta por Santos (1997).

Quando as mudas apresentaram o segundo par de folhas (40 dias após o plantio), foram selecionadas aquelas de tamanho uniforme, as quais foram transplantadas para vasos de $5 \mathrm{~L}$ de capacidade, contendo solo. O solo utilizado para enchimento dos vasos foi proveniente da camada de $0-20 \mathrm{~cm}$ de profundidade, sendo classificado como VermelhoAmarelo Câmbico, fase terraço, cujas características químicas encontram-se na Tabela 2 . 
Tabela 1 - Herbicidas e dosagens $\left(\mathrm{mL}\right.$ ou $\left.\mathrm{g} \mathrm{ha}^{-1}\right)$ aplicadas, com base no ingrediente ativo, em pós-emergência da mandioquinha-salsa

\begin{tabular}{|c|c|c|c|}
\hline \multirow{2}{*}{ Herbicida } & \multicolumn{3}{|c|}{ Dosagem } \\
\hline & Baixa & Média & Alta \\
\hline Bentazon & 600,0 & 900,0 & 960,0 \\
\hline Linuron & 900,0 & $1.350,0$ & $1.800,0$ \\
\hline Oxadiozon & 500,0 & 750,0 & $1.000,0$ \\
\hline Flazasulfuron & 50,0 & 75,0 & 100,0 \\
\hline Halosulfuron & 75,0 & 112,0 & 150,0 \\
\hline Imazamox & 28,0 & 35,0 & 42,0 \\
\hline Amônio-glufosinato & 200,0 & 300,0 & 400,0 \\
\hline Clethodim & 84,0 & (36,0 & 108,0 \\
\hline Fenoxaprop-p-ethyl & 68,2 & 90,2 & 110,0 \\
\hline Fluazifop-p-butil & 94,0 & 187,0 & 250,0 \\
\hline Propaquizafop & 100,0 & 125,0 & 150,0 \\
\hline Sethoxydim & 184,0 & 230,0 & 276,0 \\
\hline Testemunha & - & - & - \\
\hline
\end{tabular}

As plantas foram irrigadas por aspersão, de acordo com a necessidade, durante todo o periodo do experimento. As plantas daninhas que emergiram nos vasos foram eliminadas manualmente.

Os herbicidas foram aplicados 12 dias após o transplante das mudas, com um pulverizador costal pressurizado a $\mathrm{CO}_{2}$, equipado com barra de dois bicos do tipo leque 110 03, espaçados de $50 \mathrm{~cm}$, pressão de $2,3 \mathrm{kgf} \mathrm{cm}^{-2}$, calibrado para aplicar $200 \mathrm{~L} \mathrm{ha}^{-1}$ de calda. Os dados de temperatura máxima e mínima, umidade relativa e insolação registrados no período de condução do experimento encontram-se na Figura 1.

Durante a condução do experimento, os sintomas visuais de intoxicação dos herbicidas foram avaliados a cada 14 dias, atribuindo valores de 0 a $100 \%$ em função da intensidade dos sintomas, sendo 0 ausência de sintomas e

Tabela 2 - Resultados da análise química de amostras do solo utilizado no enchimento dos vasos ${ }^{\underline{1}}$

\begin{tabular}{|c|c|c|c|c|c|c|c|c|c|c|}
\hline \multirow{2}{*}{$\mathrm{pH}: \mathrm{H}_{2} \mathrm{O}$} & $\mathrm{P}$ & $\mathrm{K}$ & $\mathrm{Ca}^{2+}$ & $\mathrm{Mg}^{2+}$ & $\mathrm{Al}^{3+}$ & $\mathrm{H}^{+}+\mathrm{Al}^{3+}$ & SB & CTC & V & M.O. \\
\hline & \multicolumn{2}{|c|}{$\left(\mathrm{mg} / \mathrm{dm}^{3}\right)$} & \multicolumn{6}{|c|}{$\left(\mathrm{cmol}_{\mathrm{c}} / \mathrm{dm}^{3}\right)$} & $(\%)$ & $(\mathrm{dag} / \mathrm{kg})$ \\
\hline 5,8 & 14,6 & 146 & 3,31 & 0,51 & 0,00 & 4,62 & 4,19 & 8,81 & 47,6 & 3,08 \\
\hline
\end{tabular}

pH em água - relação 1:2,5; P e K- extrator Mehlich 1; Ca, Mg e Al - extrator KCl 1 mol L ${ }^{-1} ; \mathrm{H}+\mathrm{Al}$ - extrator Acetato de Cálcio $0,5 \mathrm{~mol} \mathrm{~L}^{-1}$; M. O.- Walkley-Black (Mat. Orgânica = C. Org. x 1,724).

Análises realizadas nos Laboratórios de Física e Ouímica do Solo do Departamento de Solos da Universidade Federal de Vicosa. UFV.

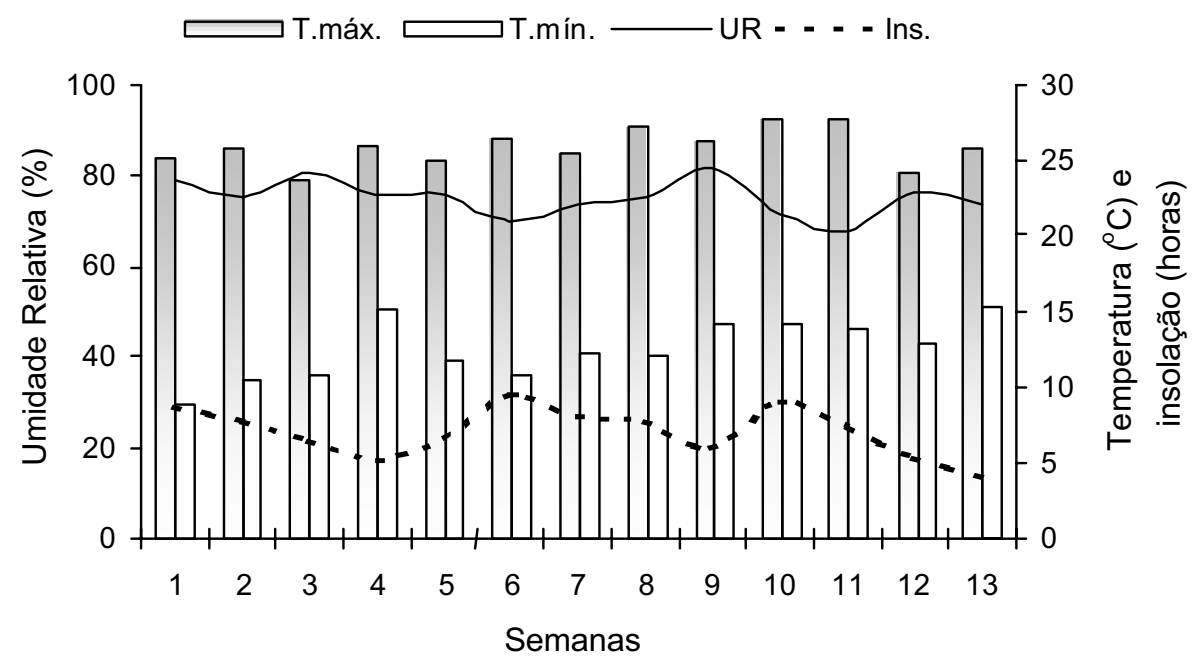

Figura 1 - Médias semanais de temperatura máxima (T.máx.), temperatura mínima (T.mín.) e insolação no período de junho a setembro de 2001 . 
$100 \%$ a morte da parte aérea da planta. Esses valores foram sempre tomados em comparação com o tratamento testemunha, sem aplicação de herbicidas (Sociedade Brasileira da Ciência das Plantas Daninhas, 1995).

Aos 49 dias após a aplicação dos tratamentos (DAA), procedeu-se à medição da altura das plantas. Em seguida, as plantas foram cortadas rente ao solo, sendo a parte subterrânea lavada em água corrente. Esses materiais foram acondicionados em sacos de papel, separadamente, e colocados em estufa de circulação de ar, a $72{ }^{\circ} \mathrm{C}$, até atingirem peso constante, para posterior avaliação da biomassa seca.

Os resultados referentes à altura de plantas e biomassa seca foram submetidos à análise de variância e fez-se o desdobramento dos efeitos de tratamento independentemente de sua significância. As médias foram comparadas pelo teste de Tukey, a 5\% de probabilidade. Os resultados de avaliação dos sintomas de intoxicação foram submetidos à análise descritiva, erro-padrão médio, pois essa característica não apresentou homogeneidade das variâncias.

\section{RESULTADOS E DISCUSSÃO}

Os resultados referentes às avaliações dos sintomas visuais de intoxicação dos herbicidas, nas doses baixa, média e alta, em plantas de mandioquinha-salsa estão representados nas Figuras 2, 3 e 4, por meio das médias e do erro-padrão.

Observou-se que as plantas de mandioquinha-salsa não toleraram os herbicidas flazasulfuron e halosulfuron nas três doses estudadas. As plantas que receberam as doses desses herbicidas atingiram $80 \%$ de toxicidade já na primeira avaliação (Figuras 2, 3 e 4). Na avaliação de sintomas aos 28 dias após a aplicação (DAA), foi observada morte da parte aérea das plantas nas três doses estudadas. A mandioquinha-salsa também não tolerou o herbicida imazamox. Nas avaliações feitas aos 28 e 42 DAA, constatou-se aumento dos sintomas de intoxicação, com niveis superiores a $80 \%$, que, apesar de não ter provocado a morte das plantas, foi suficiente para causar redução na produção de biomassa de raiz e da parte aérea das plantas (Figuras 2, 3 e 4 e Tabelas $3,4$ e 5$)$.

O herbicida bentazon causou, nas primeiras avaliações, toxicidade de $55 \%$ na dose baixa e de $70 \%$ na dose alta, porém as plantas apresentaram recuperação aos 42 DAA, reduzindo a toxicidade a 20\% (Figuras 2, 3 e 4). Todavia, ele provocou redução da biomassa seca da parte subterrânea e da altura das plantas, nas três doses avaliadas (Tabelas 3, 4 e 5).

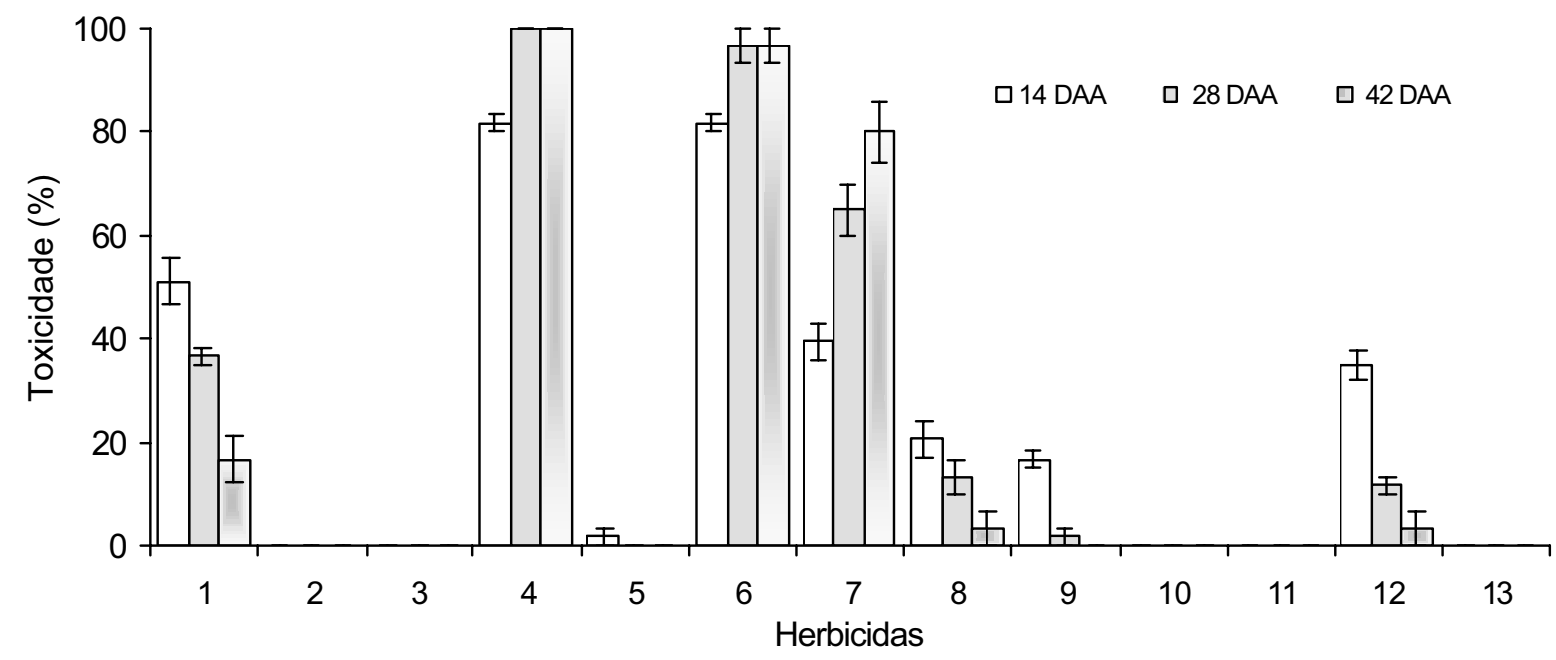

Figura 2 - Toxicidade (\%) dos herbicidas (dose baixa), aos 14, 28 e 42 DAA, aplicados em pós-emergência em mandioquinhasalsa (1 - bentazon, 2 - clethodim, 3 - fenoxaprop-p-ethyl, 4 - flazasulfuron, 5 - fluazifop-p-butil, 6 - halosulfuron, 7 imazamox, 8 - linuron, 9 - oxadiazon, 10 - propaquizafop, 11 - sethoxydim, 12 - amônio-glufosinato e 13 - testemunha). 


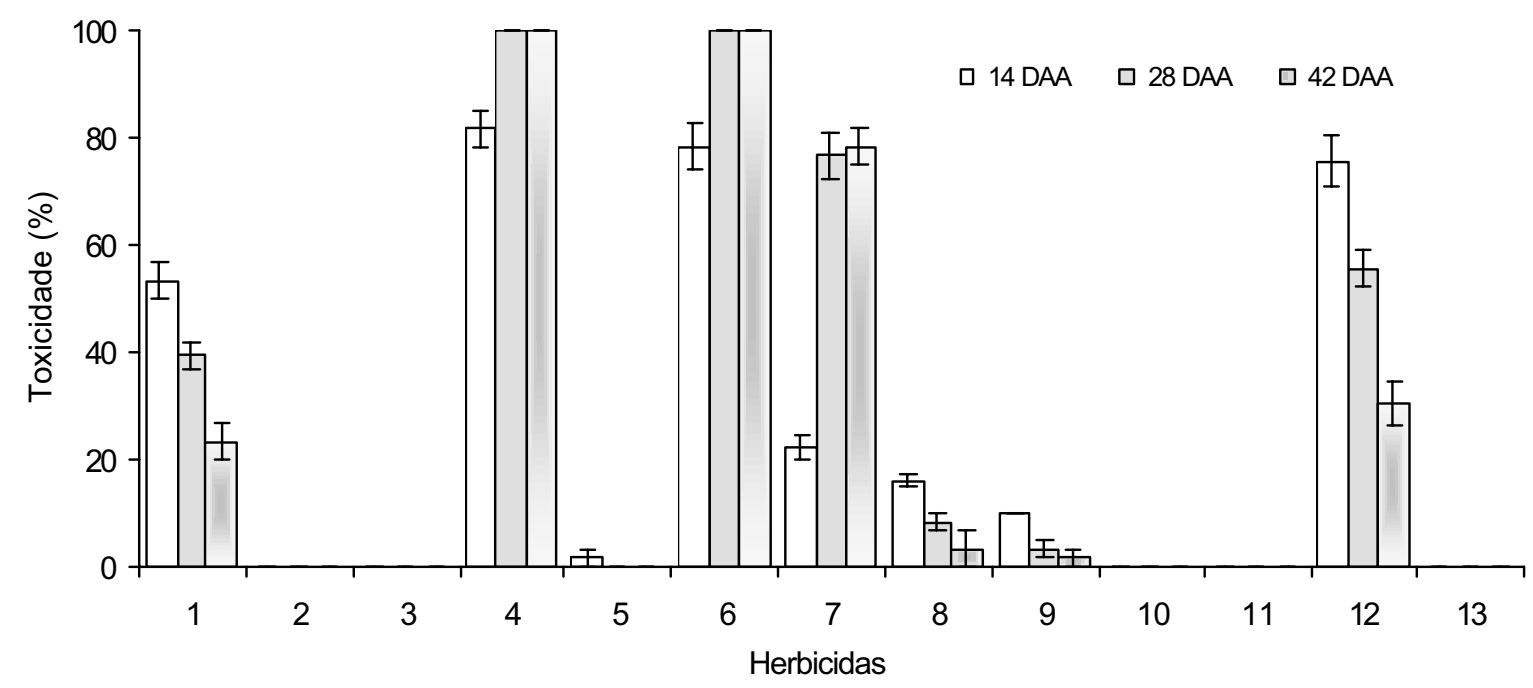

Figura 3 - Toxicidade (\%) dos herbicidas (dose média), aos 14, 28 e 42 DAA, aplicados em pós-emergência da mandioquinhasalsa (1 - bentazon, 2 - clethodim, 3 - fenoxaprop-p-ethyl, 4 - flazasulfuron, 5 - fluazifop-p-butil, 6 - halosulfuron, 7 imazamox, 8 -linuron, 9 - oxadiazon, 10 - propaquizafop, 11 - sethoxydim, 12 - amônio-glufosinato e 13 - testemunha).

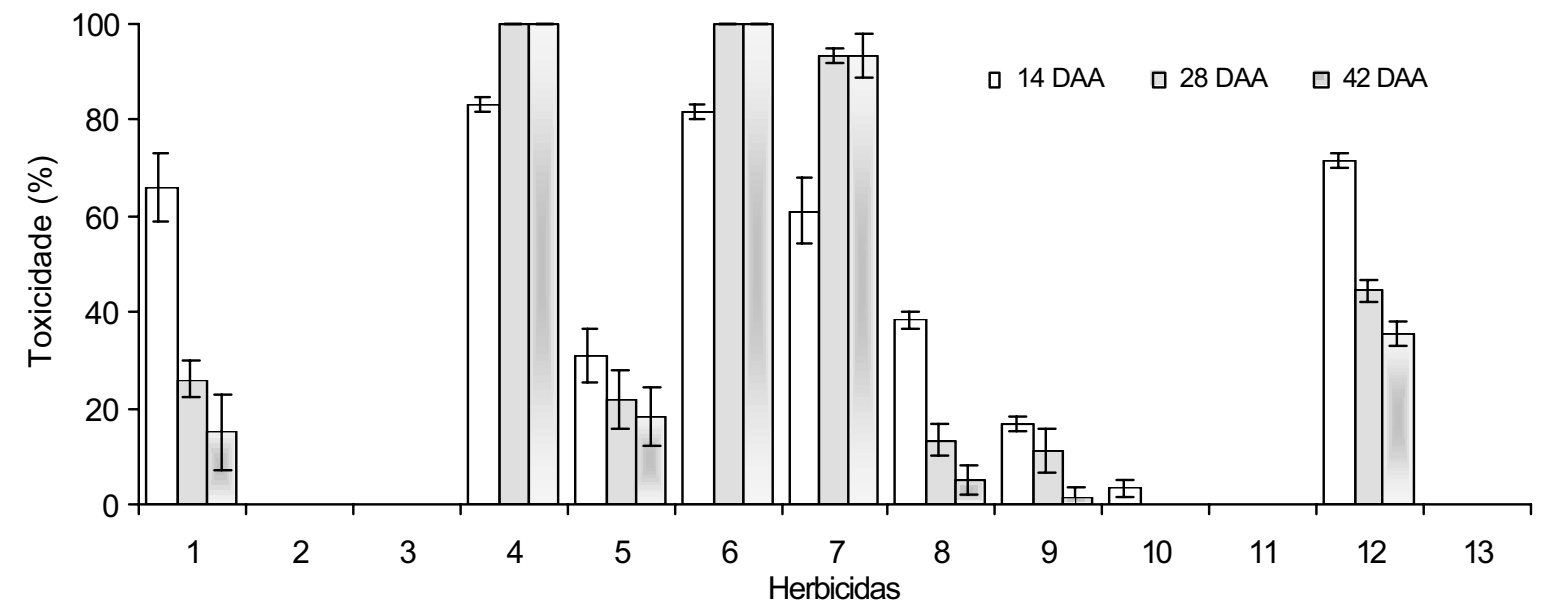

Figura 4 - Toxicidade (\%) dos herbicidas (dose alta), aos 14, 28 e 42 DAA, aplicados em pós-emergência da mandioquinha-salsa (1 - bentazon, 2 - clethodim, 3- fenoxaprop-p-ethyl, 4 - flazasulfuron, 5 - fluazifop-p-butil, 6 - halosulfuron, 7 - imazamox, 8 - linuron, 9 - oxadiazon, 10 - propaquizafop, 11 - sethoxydim, 12 - amônio-glufosinato e 13 - testemunha).

O amônio-glufosinato, nas doses baixa, média e alta, apresentou toxicidade de 35, 80 e $70 \%$, respectivamente. As plantas submetidas à menor dose apresentaram boa recuperação vegetativa aos 42 DAA, não influenciando o seu crescimento e desenvolvimento (Tabelas 3, 4 e $5)$, tornando esse produto promissor para o controle de plantas daninhas nas entrelinhas da cultura, em aplicação dirigida, uma vez que a deriva não afetaria o desenvolvimento das plantas. Entretanto, são necessários novos estudos de campo, envolvendo doses e seletividade.

Aos 14 dias após a aplicação, o linuron causou $40 \%$ de toxicidade na dose alta. O oxadiazon foi menos tóxico. Aos 28 dias após a aplicação, para ambos os herbicidas, já se observou boa recuperação das plantas, nas três doses utilizadas (Figuras 2, 3 e 4). O linuron 
na dose alta reduziu a biomassa seca da parte subterrânea, porém a altura das plantas não foi afetada por nenhuma das doses utilizadas do linuron e oxadiazon (Tabelas 3 e 5).

Tabela $\mathfrak{j}$ - Biomassa seca de parte aérea de plantas de mandioquinha-salsa, submetidas a doses (baixa, média e alta) de herbicidas, aos 49 dias após a aplicação dos tratamentos

\begin{tabular}{|c|c|c|c|c|}
\hline \multirow{3}{*}{ Herbicida } & \multicolumn{4}{|c|}{ Biomassa seca da parte aérea $(\mathrm{g})$} \\
\hline & \multicolumn{4}{|c|}{ Dose } \\
\hline & Baixa & Média & \multicolumn{2}{|l|}{ Alta } \\
\hline Bentazon & $3,54 \mathrm{~B} \quad \mathrm{~b}$ & $2,61 \mathrm{~B} \quad \mathrm{~b}$ & $4,67 \mathrm{AB}$ & a \\
\hline Clethodim & $5,54 \mathrm{~A} \quad \mathrm{a}$ & $6,07 \mathrm{AB} \quad \mathrm{a}$ & $5,52 \mathrm{~A}$ & a \\
\hline Fenoxaprop-p-ethyl & 5,75_A a & $6,40 \mathrm{~A}$ a & $5,27 \mathrm{AB}$ & a \\
\hline Fluazifop-p-butil & $6,26 \mathrm{~A}$ & $5,54 \mathrm{AB}$ & $5,42 \mathrm{AB}$ & a \\
\hline Linuron & $5,64 \mathrm{~A} \quad \mathrm{a}$ & $5,31 \mathrm{AB} \quad \mathrm{a}$ & $3,92 \mathrm{BC}$ & $\mathrm{b}$ \\
\hline Oxadiazon & $5,64 \mathrm{~A} \quad \mathrm{a}$ & $5,36 \mathrm{AB} \quad \mathrm{a}$ & $5,99 \mathrm{~A}$ & $\mathrm{a}$ \\
\hline Propaguizafop & 5,99 A & 5,17 AB a & $5,82 \mathrm{~A}$ & a \\
\hline Sethoxydim & $6,07 \mathrm{~A}$ & $5,34 \mathrm{AB} \quad \mathrm{a}$ & $5,61 \mathrm{~A}$ & $\mathrm{a}$ \\
\hline Amônio-glufosinato & $6,06 \mathrm{~A}$ & $2,75 \mathrm{C} \quad \mathrm{b}$ & $2,84 \mathrm{C}$ & $\mathrm{b}$ \\
\hline Flazasulfuron & $0,00 \mathrm{c}$ & $0,00 \mathrm{D} \quad \mathrm{a}$ & 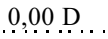 & a \\
\hline 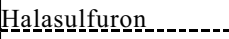 & $0,17 \mathrm{c}$ & 0_00_D__a & 然. & a \\
\hline Imazamox & $0,93 \mathrm{C}$ & $1,37 \mathrm{CD} \quad \mathrm{a}$ & $0,51 \mathrm{D}$ & $\mathrm{a}$ \\
\hline Testemunha & $5,90 \mathrm{~A}$ & $5,82 \mathrm{AB} \quad \mathrm{a}$ & $5,80 \mathrm{~A}$ & $\mathrm{a}$ \\
\hline $\mathrm{CV}(\%)$ & & 13,20 & & \\
\hline
\end{tabular}

Médias seguidas da mesma letra maiúscula, na coluna, e da mesma letra minúscula, na linha, não diferem entre si pelo teste de Tukey a $5 \%$ de probabilidade.

Tabela 4 - Biomassa seca da parte subterrânea de plantas de mandioquinha-salsa, submetidas a doses de herbicidas (baixa, média e alta), aos 49 dias após a aplicação dos tratamentos

\begin{tabular}{|c|c|c|c|}
\hline \multirow{3}{*}{ Herbicida } & \multicolumn{3}{|c|}{ Biomassa seca da parte subterrânea $(\mathrm{g})$} \\
\hline & \multicolumn{3}{|c|}{ Dose } \\
\hline & Baixa & Média & Alta \\
\hline Bentazon & $2,18 \mathrm{C}$ & $1,54 \mathrm{DE} \quad \mathrm{b}$ & $1,88 \mathrm{DE}$ \\
\hline Clethodim & $3,34 \mathrm{~A}$ & $3,20 \mathrm{AB} \quad \mathrm{a}$ & $2,89 \mathrm{ABC} \quad \mathrm{a}$ \\
\hline Fenoxaprop-p-ethyl & $3,16 \mathrm{AB}, \mathrm{a}$ & $3,38 \mathrm{~A}$ & $3,45 \mathrm{~A}$ \\
\hline Fluazifop-p-butil & $3,35 \mathrm{~A} \ldots \ldots$ & $3.30 \mathrm{~A}$ & $2,32, \mathrm{CD}$ \\
\hline Linuron & $2,55 \mathrm{BC} \quad \mathrm{a}$ & $2,50 \mathrm{BC} \quad \mathrm{a}$ & $2,36 \mathrm{CD}$ \\
\hline Oxadiazon & $3,05 \mathrm{AB} \quad \mathrm{a}$ & $2,80 \mathrm{ABC}$ a & $2,59 \mathrm{BCD}$ \\
\hline Propaguizafop & $3,11 \mathrm{AB} \ldots \mathrm{a}$ & $3,30 \mathrm{~A}$ & $3,24 \mathrm{AB}$ \\
\hline Sethoxydim & $3,29 \mathrm{AB} \ldots$ & $3,14 \mathrm{AB}$ & $3,17 \mathrm{AB}$ \\
\hline Amônio-glufos & 2,69 ABC..a & 2.24 CD & $1,40 \mathrm{EF}$ \\
\hline Flazasulfuron & $0,00 \mathrm{E}$ & $0,0 \mathrm{~F}$ & $0,00 \mathrm{~F}$ \\
\hline Halasulfuron & $0,27 \mathrm{DE}$ & $0,0 \mathrm{~F}$ & $0,00 \mathrm{G}$ \\
\hline Imazamox & $0,85 \mathrm{D}$. & $1,28 \mathrm{E}$ & $0,77 \mathrm{G}$ \\
\hline Testemunha & $2,93 \mathrm{AB}$ & $3,2 \mathrm{AB}$ & $3,25 \mathrm{AB}$ \\
\hline CV (\%) & & 11.99 & \\
\hline
\end{tabular}

Médias seguidas da mesma letra maiúscula, na coluna, e da mesma letra minúscula, na linha, não diferem entre si pelo teste de Tukey a $5 \%$ de probabilidade.
Tabela 5 - Altura de plantas de mandioquinha-salsa, submetidas a doses (baixa, média e alta) de herbicidas, aos 49 dias após a aplicação dos tratamentos

\begin{tabular}{|c|c|c|c|}
\hline \multirow{3}{*}{ Herbicida } & \multicolumn{3}{|c|}{$\begin{array}{l}\text { Altura das plantas de mandioquinha-salsa } \\
\qquad(\mathrm{cm})\end{array}$} \\
\hline & \multicolumn{3}{|c|}{ Dose } \\
\hline & Baixa & Média & Alta \\
\hline Bentazon & $31,11 \mathrm{~A}, \mathrm{~b}$ & $27,99 \mathrm{BC}$ b & $36,30 \mathrm{~A}$ \\
\hline Clethodim. & $36,89 . A$. a & $36,92 \mathrm{~A}$ & $34,59 \mathrm{~A}$ \\
\hline Fenoxaprop-p-ethyl & $37,36 . \mathrm{A} \ldots$ a & 36.77.A. a & $35,91 \mathrm{~A}$. \\
\hline Fluazifop-p-butil & $37,17 \mathrm{~A} \quad \mathrm{a}$ & $35,59 \mathrm{~A} \quad \mathrm{a}$ & $34,73 \mathrm{~A}$ \\
\hline Linuron & $36,71 \mathrm{~A} \quad \mathrm{a}$ & $34,42 \mathrm{AB}$ a & $33,52 \mathrm{~A}$ \\
\hline Oxadiazon & $37,85 . \mathrm{A} \ldots \mathrm{a}$ & $36,44 \mathrm{~A}$ & $37,18 \mathrm{~A}$ \\
\hline Propa & $36,00, A \ldots$ & 33,07 AB a & $37,59 \mathrm{~A}$ \\
\hline Sethoxydim & $35,39 \mathrm{~A}$ & $31,59 \mathrm{AB}$ a & $35,37 \mathrm{~A}$ \\
\hline Amônio-glufosinato & $35,04 \mathrm{~A}$ & $23,48 \mathrm{C}$ & $25,77 \mathrm{~B}$ \\
\hline Flazasulfuron & $0,00 \mathrm{C}$ & $0,00 \mathrm{E}$ & $0,00 \mathrm{D}$ \\
\hline Halasulfuron & $0,00 . . . \mathrm{a}$ & $0,00 \mathrm{E}$ & $0,00 \mathrm{D}$ \\
\hline Imazamox & $15,00 \mathrm{~B}$ & $13,20 \mathrm{D}$ & $13,77 \mathrm{C}$ \\
\hline Testemunha & $36.39 \mathrm{~A}$ & $35.70 \mathrm{~A}$ & $35.70 \mathrm{~A}$ \\
\hline $\mathrm{CV}(\%)$ & & 8,75 & \\
\hline
\end{tabular}

Médias seguidas da mesma letra maiúscula, na coluna, e da mesma letra minúscula, na linha, não diferem, entre si, pelo teste de Tukey a $5 \%$ de probabilidade.

Os herbicidas clethodim, sethoxydim, fenoxaprop-p-ethyl e propaquizafop não causaram quaisquer sintomas de toxicidade às plantas de mandioquinha-salsa (Figuras 2, 3 e 4) e também não afetaram a produção de biomassa seca e altura das plantas (Tabelas 3, 4 e 5). O modo de ação primário destes herbicidas consiste na inibição da sintese de ácidos graxos, através da inibição da enzima Acetil Coenzima-A Carboxilase (ACCase). Esta enzima regula uma reação-chave no início da biossintese de lipídeos (converte o Acetil Coenzima-A em Malonil Coenzima-A). A ACCase presente em gramíneas é, geralmente, sensivel à inibição por estes herbicidas, entretanto, em espécies monocotiledôneas não-gramíneas e dicotiledôneas ela parece não ser afetada (Thill, 2000).

Segundo Silva et al. (2000), a diferença na tolerância entre espécies gramineas e folhas largas é muito grande. Enquanto $0,1 \mu \mathrm{M}$ de haloxyfop provocou $42 \%$ de inibição da incorporação de acetato em células de milho, para causar $50 \%$ de inibição em células de soja foi necessária uma concentração 47 vezes maior. De acordo com estes autores, também há diferença entre a atividade de isômeros e as formulações. Desse modo, o mecanismo de 
seletividade entre dicotiledôneas e espécies gramineas é o sítio de ação da ACCase. Nenhuma diferença na absorção e translocação tem sido relatada entre dicotiledôneas e gramíneas (Hess \& Weller, 2000; Thill, 2000).

O fluazifop-p-butil, também usado especificamente para controlar gramineas perenes e anuais (Weller, 2000), quando aplicado em dose alta, causou aproximadamente $30 \%$ de toxicidade na mandioquinha-salsa, observada aos 14, 28 e 42 dias após sua aplicação (Figura 4). Este herbicida também afetou a produção de biomassa seca subterrânea na dose alta (250 g i.a. ha-1) (Tabela 2). Vidal et al. (2000), estudando a seletividade do herbicida fluazifop-p-butil a cucurbitáceas, verificaram que o melão e o pepino são suscetiveis às doses de 376 e 752 g i.a.ha-1, sugerindo que a sensibilidade aos herbicidas inibidores de ACCase pode variar entre as espécies de dicotiledôneas.

Considerando os herbicidas aplicados em pós-emergência, conclui-se que flazasulfuron, halosulfuron, imazamox e bentazon não foram seletivos para a cultura. A mandioquinha-salsa também apresentou baixa tolerância ao herbicida amônio-glufosinato nas doses média e alta e, na menor dose, não influenciou o desenvolvimento das plantas. Fluazifop-pethyl, oxadiazon e linuron mostraram-se promissores para manejo de plantas daninhas nesta cultura, nas menores doses utilizadas. Os herbicidas fenoxaprop-p-ethyl, clethodim, propaquizafop e sethoxydim foram seletivos, nas três doses utilizadas, para a cultura da mandioquinha-salsa.

\section{AGRADECIMENTOS}

À FAPEMIG, pelo apoio financeiro ao projeto e pela bolsa de pesquisa, modalidade Aperfeiçoamento, concedida a Pedro Carlos Pereira.

\section{LITERATURA CITADA}

CASALI, V. W. D.; SEDIYAMA, M. A. N. Origem e botânica da batata baroa. Inf. Agropec., v. 19, n. 190, p. 13-14, 1997.
GREY, L. G.; BRIDGES, D. C.; NeSMITH, D. S. Tolerance of cucurbits to herbicides Clomazone, Ethalfluralin, and Pendimenthalin. I. Summer Squash. HortiScience, v. 35, n. 4, p. $632-636,2000$.

HARRISON, F. H.; DUKES, P. P. D. Sensitivity of four sweet potato clones to Metribuzin herbicide. HortiScience, v. 31, n. 5 , p. 846-847, 1996.

HESS, F. D.; WELLER, S. C. Principles of selective weed control with herbicides. In: Herbicide action. West Laffaetti: Purdue University; 2000. 942 p.

MADEIRA, N. R.; SANTOS, F. F.; SOUZA, R. J. Desempenho de clones de mandioquinha-salsa (Arracacia xanthorrhiza Bancroft) na região de Lavras-MG. Ci. Agrotec., v. 26, n. 4, p. 711-718, 2002.

SANTOS, F. F. Utilização de mudas juvenis e do préenraizamento no impedimento da floração em mandioquinha-salsa. Inf. Agrop., v. 19, n. 190, p. 27-28, 1997.

SILVA, A. A. et al. Controle de plantas daninhas. Brasília, DF: ABEAS, 2000. 260 p. (Curso de Tutoria à Distância. Curso de Proteção de Plantas, Módulo 3).

SOCIEDADE BRASILEIRA DA CIÊNCIA DAS PLANTAS DANINHAS - SBCPD. Procedimentos para instalação, avaliação e análise de experimentos com herbicidas. Londrina: 1995. $42 \mathrm{p}$.

THILL, D. Integrated weed management. In: Herbicide action. West Lafaietti: Purdue University, 2000. 942 p.

VIDAL, R. A. et al. Seletividade do herbicida fluazifop-pbutil para cucurbitáceas. Planta Daninha, v. 18, n. 3, p. $413-417,2000$.

WELLER, S. C. Classification of herbicides. In: Herbicide action. West Lafaietti: Purdue University, 2000. 942 p.

ZAGONEL, J.; REGHIN, M. Y.; VENÂNCIO, W. S. Controle pós-emergente de plantas daninhas em cenoura. Hort. Bras., v. 17, n. 1, p. 69-71, 1999.

ZAGONEL, J.; REGHIN, M. Y.; VENÂNCIO, W. S. Avaliação de herbicidas de pós-emergência na cultura da cebola. Hort. Bras., v. 18, n. 3, p. 229-231, 2000.

ZANIN, A. C. W.; CASALI, V. W. D. Efeitos climáticos sobre a mandioquinha-salsa. Inf. Agropec., v. 10, n. 120, p. 13-15, 1984. 